\title{
The Influence of Interactive Learning Media Based on Augmented Reality on the Achievement of Art Learning Result
}

\author{
Jenny IS Poerwanti ${ }^{1}$, Tri Budiharto ${ }^{2}$, Sri Marmoah ${ }^{3}$ \\ \{jenny_isp@staff.uns.ac.id ${ }^{1}$, tribudhiharto_pgsd@staff.uns.ac.id ${ }^{2}$, marmuah@staff.uns.ac.id $\left.{ }^{3}\right\}$ \\ 1,2,3 Teacher Training and Education Faculty, Universitas Sebelas Maret, Surakarta, Indonesia
}

\begin{abstract}
Abstarct. Interactive media-based art learning using AR makes the learning process become active, creative, and meaningful. The purpose of this research are to know the influence of interactive learning media based on augmented reality on students academic achievement on art learning, and to analyze students opinion about the interactive use of media based on augmented. The research design was a quasi-experimental with pre-test post-test control group design. The study was conducted with 80 students in the elementary teacher education. The study was to analyze the different influence of interactive media based on augmented reality with conventional learning without using AR. It was found that the use of AR had a positive influence on students' academic achievement in art learning. These results indicate that $\mathrm{AR}$ applications are effective in improving the achievement of art learning outcomes. In addition to the qualitative data gathered from the students using questionnaire showed that AR application can be used as an interest in learning art, $87 \%$ offered positive responses concerning the influences of the AR application, while $13 \%$ stated negative opinions. The results of this study can be used as a guide for planning and the use of Augmented reality (AR) in the subsequent teaching and learning process.
\end{abstract}

Keywords: elementary, teacher education, and augmented reality.

\section{INTRODUCTION}

One important aspect in art education is the appreciation of artwork. Appreciate the artwork is a combination of aspects of observation and taste (appreciation), so it takes a sense of sense in living artwork. Through art appreciation activities can train the sensitivity of learners themselves and others in appreciating his own artwork as well as others. Many ways of learning that can be done in art activities in college, apart from being creative, frequently asked questions, appreciation activities have become a lot of things done in schools, showing the works that are in a slide or visiting museums and exhibitions. The way of learning carried out by each student varies greatly depending on the needs of the students. In learning art 
requires media that can help students in achieving learning objectives. The media used can be either interactive or un interactive media.

The progress of science and technology has a major influence on human life, as well as on the development of learning in achieving effective and efficient learning goals. In addition, the advancement of science and technology has influenced the development of the use of teaching aids in schools and other educational institutions. This development play a role in a development instructional Media. Instructional Media becoming more attractive and more concise although it does not reduce the essence of the material. One of the development of learning media which is currently still new is the media learning using Augmented Reality

Based on needs analysis, art learning has not used technology- based interactive learning media. This makes students less motivated to produce works of art such as mosaic works, montage, and collages. Learning still uses conventional strategies that begin with a brief explanation of how to produce works as stated in the text book. ${ }^{[1]}$.Other findings is that students' artworks area a little due to lack of learning motivation and low learning outcomes compared to other subjects. The study found, almost all students stated that they needed an interactive media based on augmented reality. This can encourage students to work more actively in producing art and motivate them to appreciate the artwork produced by themselves and others. In addition, the academic achievement of students are poor, because they experience conventional teaching methods. Learning strategies used in teaching fine arts have not fully facilitated the creative development of students. This is because conventional teaching does not develop meaningful learning experiences, such as expected contextual and collaborative learning methods in constructivist teaching strategies. ${ }^{[2]}$. Based on the matters described above, it takes an interesting learning media that can motivate, and generate a sense of interest of students to focus on learning and can clarify the material delivered. Many multimedia-based learning media are used today, but only limited use pointers, such as the mouse or keyboard.

Most mobile devices also support the latest visualization platforms such as augmented reality (AR), which allows users to see the real world enhanced by three-dimensional (3D) content generated by computers. Using AR can easily display virtual objects, students can also access content, visual information contextually in class. AR is a technology that is developing rapidly at this time, especially in its use in the world of education. The use of AR in the art learning process can make the interaction more active because it can be integrated into the material and plan of learning in the classroom ${ }^{[3]}$.

The development of augmented reality is very rapid because the technology presented can visualize virtual objects that have been designed to be displayed so that looks real. In addition to presenting new innovations in its application, augmented reality too presents a new dimension that is to detect objects that have been determined in advance and allow the user interacts with the application. AR can be used to help visualize abstract concepts for understanding and structuring object models[4].

A study conducted at the University of Georgia states that the use of technology in classroom learning has a positive influence in improving the quality of learning processes and outcomes. This is because AR can motivate students to be more active in receiving learning material. [5].The use of AR which is combined in the learning process especially in art can produce students' imagination in producing artwork [6].Students' motivation and interest in learning also increased this because they were interested in the images displayed with AR technology [7] [8]. The formulation of this research problem is to determine the influence of AR-based interactive media on the achievement of student art learning outcomes in art learning 


\subsection{Augmented Reality}

Augmented means an added size or value, whereas Reality is something that can actually be seen or felt in real terms[9]. Augmented Reality often abbreviated as AR is a technology that combines virtual objects into real environments in real time. Augmented Reality can allow users to see the real world with virtual objects generated with computers that are poured out in the real world. 2.2 Autodeks 3ds Max Autodesk Applications 3ds max is a popular 3D visualization and animation software. Augmented reality is a term used to combine the real world and virtual world created by computers so that the boundary between the two becomes very slim [10]. Virtual objects are added only as substitutes for real objects. The purpose of Augmented reality is to simplify real objects by carrying virtual objects. so that information is not only for users directly but also for each user associated with the user interface of the real object. In general, augmented reality is the incorporation of virtual objects with real objects in order to interact in real time in $3 \mathrm{D}[11]$.

AR technology is very potential to be used as a means of education. One of the advantages that can be obtained from the application of AR to be applied in the learning that is increasing the understanding of the object being studied. AR is more effective as a learning medium other than other media such as books, video, or the use of ordinary computers[12]. Technology AR, is one of the renewals used in various fields of science so that AR has the opportunity to continue to be developed in any field. AR has the potential to change education to become more efficient in th e same way that computers and Internet have.

The results of published studies show that the use of AR technology in the classroom learning process can improve academic achievement [13] [14] while the same study was also conducted at the primary, secondary and high education level, there are no studies exploring its impact use of AR in primary school teacher education about academic achievement.

\subsection{Augmented Reality as Media in Art Education}

One type of technology that can be used in the process of learning art is AR. AR technology can be used in conjunction with mobile devices when teaching and learning art in class, which has been proven to help students understand and make the learning process more interactive, effective and efficient [15] [16]. The purpose of AR is to add, or improve our real world environment by adding images, videos, information, or audio to it, which are used as a medium to convey messages. [17]. If a student with a mobile device wants to access AR, they will scan the trigger image, which will then produce an AR response [18]. The use of AR can make students more concentrated in accepting teaching material, because the use of AR makes the learning process centered on students and can stimulate interest. This allows students to explore the world interactively, so this study wants to use AR as a medium in art education classes. By using augmented reality media, it is expected to increase students' artistic appreciation. AR technology can be utilized through various media including desktops, cellular devices, and smart phones. AR technology is a portable tool and can adapt to various images and scenarios, which can be used in classroom learning. AR can be used to improve content and instruction in traditional classes and make learning more active, interactive especially to display mosaic, collage and montage works

Augmented reality was widely known in 1997, which is a combination of real and virtual data, can interact with real time, and is used in a $3 \mathrm{D}$ environment. The development of the use of AR is very rapid as is the case with the development of cellular technology. AR and cellular technology can be used anywhere including being used in the process of learning art in class 
[19]. The ability to make AR more mobile and can create opportunities in the world of education. AR can motivate students to learn more actively especially in creating artworks, and give students the opportunity to, "manipulate virtual objects or representations of real objects that are impossible to hold. Besides that AR can improve students' skills in drawing objects.

The use of AR in this study is as a medium in art learning especially to produce mosaic works, collages and montage. AR is used to use markers to make visual arts learning activities. The artwork displayed is mosaic, collage, and montage and other works of art. AR provides the ability to display images, text, videos, and audio components to existing images or spaces. Using marker-based codes to provide additional information on mobile devices is very easy to use. The teacher can use a simple QR (Quick Response) two-dimensional code to associate information such as text, URLs, or other data.

Interactive learning media based on Augmented Reality is used in art learning by combining pictorial paper and virtual reality. Markers on pictorial paper will be captured by a webcam camera and then processed and will display videos about artwork (mosaics, collages and montage) on the screen in real time. By combining the real world in the process of learning art, it can stimulate imagination, and students are motivated to produce artwork and appreciate work. Images shown on AR can stimulate students' imagination in producing good drawing works.

Augmented reality is classified based on the presence or absence of markers: marker and markerless [20]. Markers are photos of real objects or artificial images with unique patterns. AR marker is pattern recognition that calculates the position, orientation, and scale of an AR object. The AR method is an unmarked AR tracking method that uses objects in the real world as an ark or without using artificial markers. A good marker is a marker that can be easily recognized and relied upon under any conditions [21]. For example, in conditions when the light is low and the position of the camera moves, a good marker will still be read by the AR system clearly.

\section{METHOD}

This study used a quasi-experimental design, with a control and experiment group. Each group was given a pre-test and post-test. The design is used to increase the possibility of having the same group in terms of the variables under study. The study sample consisted of 80 students who attended art lectures in the fourth semester in primary school teacher education at Sebelas Maret University. To determine the number of students who entered the control and experimental groups conducted randomly so that each student has the same opportunity as the research subject The method used to answer research questions, uses a quantitative approach. This is based on several considerations such as studies needed to measure variables and specifically to assess the effect of these variables on outcomes. Experimental groups used interactive learning media based on augmented reality. In the realization of learning media, the manufacture of products is done by using Unity 3D software and vuforia SDK as supporting the development of Augmented Reality. The coding process is carried out using Microsoft Visual Studio 2012 software and for the process of creating object resources using the X7 and Blender corel draw applications.

Augmented Reality which is operated on smart- phones with the Android operating system, accompanied by fine art teaching materials. Teaching materials contain instructions for use, summary of material, and marker images. The results of the realization of the developed learning media will be presented as follows. 


\section{FINDINGS AND DISCUSSION}

To assess the result of art learning of both groups, paired-sample and independent sample t-tests were applied Tables 1 and 2 show the result of art learning of the control and experimental groups based on paired-sample t-test results. Pre-test scores of both groups represent students' prior knowledge in art learning which has been acquired from test and documentaries. The post-test scores of the control group represent the result of art learning of students through the use of the conventional art textbooks. While for the experimental group, the post-test scores represent students learning performance through the intervention of using interactive media based of Augmented Reality.

Tabel 1. Result of art learning for the control group

\begin{tabular}{|c|c|c|c|c|c|}
\hline & $\mathrm{N}$ & Minimum & Maximum & Mean & Std. Deviation \\
\hline Pretest & 40 & 56.00 & 80.00 & 65.8500 & 8.34681 \\
\hline Postest & 40 & 70.00 & 85.00 & 75.1750 & 4.65688 \\
\hline Valid N (listwise) & 40 & & & & \\
\hline
\end{tabular}

This study also examined whether the achievement of student learning outcomes in the experimental group was superior compared to the control group using an independent sample t-test. Table 5 compares the achievement of student learning outcomes in the control group and the experimental group using an independent sample t-test. The results showed that the average score of the pre-test for the two groups differed significantly. Furthermore, this study assessed whether there were significant differences in the scores of achievement of art learning on the post-test scores for the two groups based on the results from the independent sample t-test. The results showed that the post-test scores for the two experimental groups and the control group differed significantly. In this case the achievement of art learning outcomes in the experimental group taught using AR was higher than the control group taught without using AR.

Tabel 2. Comparing score of art learning between control and experimental groups

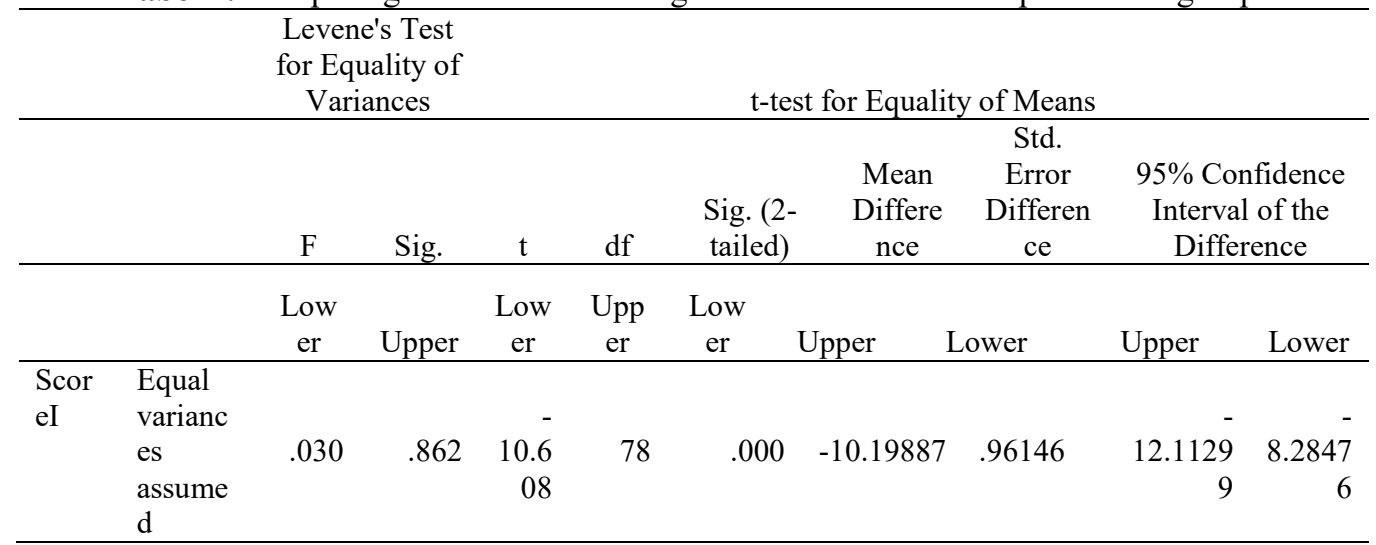




\begin{tabular}{|c|c|c|c|c|c|c|c|c|}
\hline & $\begin{array}{l}\text { Equal } \\
\text { varianc } \\
\text { es not } \\
\text { assume } \\
\text { d }\end{array}$ & $\begin{array}{r}- \\
10.5 \\
91\end{array}$ & $\begin{array}{r}77.0 \\
2\end{array}$ & .000 & -10.19887 & .96296 & $\begin{array}{r}- \\
72.1163 \\
7\end{array}$ & $\begin{array}{r}8.2813 \\
8\end{array}$ \\
\hline & Group & $\mathrm{N}$ & & Mean & Std & Deviation & \multicolumn{2}{|c|}{$\begin{array}{c}\text { Std. Error } \\
\text { Mean }\end{array}$} \\
\hline \multirow[t]{2}{*}{ Score } & Group 1 & & 40 & \multicolumn{2}{|c|}{74.9231} & 4.4330 & \multicolumn{2}{|r|}{.70985} \\
\hline & Group 2 & & 40 & \multicolumn{2}{|c|}{85.1220} & 4.16650 & \multicolumn{2}{|r|}{.65070} \\
\hline
\end{tabular}

From Table 2, the results of hypothesis testing in table 2 obtained two-sided significance of $0.00<0.05$, so that based on decision-making in the independent t-test the T-test sample, concluded that Ho was rejected and Ha was accepted, It means there significant differences between the results of art learning taught using interactive media based on augmented reality in the experimental class with those taught to use art textbooks, in the control class.

The sore of art learning outcomes that are taught by using augmented reality-based interactive media than those taught by using art textbooks. In other words, the use of augmented reality in art learning is better than using textbooks. The findings of students' opinions about the use of the augmented reality (AR) application in art learning are provided below:

(1) Influence of the AR application in terms of making the classes more fun. All of the students

(2) Students stated that the AR application made the classes more enjoyable. Their reasons were: the application itself is fun, it facilities and learning, the students can be active interact with the application using the markers (object)

(3) Students stated that the AR made the classes more cooperative on understanding the topic

The experimental design consists of control class groups taught without using AR and experimental class groups taught using AR. The students in the experimental group used interactive media based on augmented reality, while the students in the control group used the art book which was the conventional method of learning [22].

Furthermore, the Paired T-Test sample illustrates the significant level for all data collected. In addition, the results of the scores indicate that there are significant differences after augmented based interactive media is used in art learning. In other words, there is a significant influence on increasing the score of art learning outcomes that use interactive media based on augmented reality compared to only using art books.

\section{CONCLUSION}

The conclusion of the research is, the use of augmented reality-based interactive media has a significant influence on the achievement of art learning outcomes. in other words the use of interactive media based on augmented reality in art learning is better than just using art textbook. This is an advantage in using AR technology. Content can also be personalized for something you want to learn, such as visualizing images of fine art. The benefit of AR learning is that it can increase students' imagination in producing artwork. Researchers have suggested that the AR technology is suitable to be implemented in teaching and learning and also been tested in a real classroom environment. AR has made a positive impact among the students in term of performing an effective in-class assessment. Apart from that, AR 
successfully combined the education and entertainment activities together, which motivate the students to perform well.

\section{REFERENCES}

[1] J. Indrastoeti and T. Tribudiharto, "Analysis of Students' Need for Augmented Reality As An Art Learning Medium in Primary School Teacher Education at Universitas Sebelas Maret," Int. J. Educ. Res. Rev., vol. 3, no. 3, pp. 86-92, 2018.

[2] R. DeVries, B. Zan, C. Hildebrandt, R. Edmiaston, and C. Sales, Developing constructivist early childhood curriculum: Practical, principle, and activities. New York: Teachers College Press., 2002.

[3] M. M. O. da Silva, R. Roberto, and V. Teichrieb, "Evaluation of Augmented Reality Technology in the English Language Field," An. do XXVI Simpósio Bras. Informática na Educ. (SBIE 2015), vol. 1, no. Sbie, p. 577, 2015.

[4] I. Mustaqim and N. Kurniawan, "Pengembangan Media Pembelajaran Berbasis Augmented Reality," Lentera Pendidik. J. Ilmu Tarb. dan Kegur., vol. 21, no. 1, pp. 59$72,2016$.

[5] J. M. Brill and C. Galloway, "Perils and promises: University instructors' integration of technology in classroom-based practices," Br. J. Educ. Technol., vol. 38, no. 1, pp. 95$105,2007$.

[6] D. D’Souza, U. Singh, D. Sharma, and P. Ranjan, Educational technology in teaching and learning: Prospects and challenges. Patna: Patna Women's College, 2013.

[7] J. A. Delello, "Insights from pre-service teachers using science-based augmented reality," J. Comput. Educ., vol. 1, no. 4, pp. 295-311, 2014.

[8] D. Pérez-López and M. Contero, "Delivering educational multimedia contents through an augmented reality application: A case study on its impact on knowledge acquisition and retention," Turkish Online J. Educ. Technol., vol. 12, no. 4, pp. 19-28, 2013.

[9] J. Carmigniani and B. Furht, Handbook of Augmented Reality. 2011.

[10] A. Afissunani, A. Saleh, and M. H. Assidiqi, Multi Marker Augmented Reality Untuk Aplikasi Magic Book. Surabaya: Institut Teknologi Sepuluh Nopember,.

[11] R. Azuma, "A survey of augmented reality," Presence Teleoperators Virtual Environ., vol. 6, no. 4, pp. 355-385, 1997.

[12] I. Radu, "Augmented reality in education: A meta-review and cross-media analysis," Pers. Ubiquitous Comput., vol. 18, no. 6, pp. 1533-1543, 2014.

[13] B. E. Shelton and N. R. Hedley, "Using augmented reality for teaching Earth-Sun relationships to undergraduate geography students," ART 2002 - 1st IEEE Int. Augment. Real. Toolkit Work. Proc., 2002.

[14] X. Zhang et al., "High performance Li-CO2 batteries with NiO-CNT cathodes," $J$. Mater. Chem. A, vol. 6, no. 6, pp. 2792-2796, 2018.

[15] M. Billinghurst, H. Kato, and I. Poupyrev, "The MagicBook - Moving seamlessly between reality and virtuality," IEEE Comput. Graph. Appl., vol. 21, no. 3, pp. 6-8, 2001.

[16] A. Clark and A. Dünser, "An interactive augmented reality coloring book," IEEE Symp. 3D User Interfaces 2012, 3DUI 2012 - Proc., no. March 2012, pp. 7-10, 2012.

[17] K. Bonsor, "How augmented reality works," 2016. .

[18] P. Brown, "How to transform your classroom with augmented," 2015. .

[19] C. Arth, R. Grasset, L. Gruber, T. Langlotz, A. Mulloni, and D. Wagner, "The History of Mobile Augmented Reality," no. May, 2015.

[20] V. Geroimenko, "Augmented reality technology and art: The analysis and visualization of evolving conceptual models," Proc. Int. Conf. Inf. Vis., pp. 445-453, 2012. 
[21] S. Siltanen, "Theory and applications of marker based augmented reality," no. January, pp. 2-3, 2016.

[22] K. Saddhono and M. Rohmadi, "A Sociolinguistics Study on the Use of the Javanese Language in the Learning Process in Primary Schools in Surakarta, Central Java, Indonesia." Int. Edu. Stu., vol. 7 no.6 pp 25-30, 2014 